\title{
Gastric Secretion in Relation to Mucosal Blood Flow Studied by a Clearance Technic*
}

\author{
Eugene D. Jacobson, $\nmid$ Ray H. Linford, and Morton I. Grossman \\ (From the Veterans Administration Center and the Department of Physiology, University of \\ California at Los Angeles Center for the Health Sciences, Los Angeles, Calif.)
}

There is a considerable body of evidence suggesting that secretion and blood flow in the stomach vary together (1-6) and an equally impressive array of studies that speaks against such a relationship (7-11). In attempting to evaluate a possible relationship between gastric blood flow and secretion we are confronted with problems that are basically methodological (12). Nearly all of the investigations cited have been either acute experiments on anesthetized and traumatized animals or chronic observations of unanesthetized humans in which nonspecific gastric mucosal changes have been used to gauge gastric blood flow. In the acute experiments both blood flow and secretion are subject to the profound but unmeasured influences of anesthetics and surgical stress, which can camouflage a relationship. In the chronic studies the color or temperature of the mucosa or the size of microcirculatory vessels has been used as an "index" of mucosal blood flow. Unfortunately these indexes do not measure blood flow: mucosal color and vessel size are estimates of mucosal blood volume, and mucosal temperature reflects deep body temperature, not blood flow. In short, the available evidence on the subject of a relationship between blood flow and secretion in the stomach comes from experiments in which either the state of the preparation or the methods of measuring blood flow was unreliable.

We established four requirements that we felt would have to be satisfied for a study of gastric secretory and circulatory function to yield infor-

\footnotetext{
* Submitted for publication April 14, 1965 ; accepted September 16, 1965.

A partial report of this work was read before the Western Section Meeting of the American Federation for Clinical Research, January 29, 1965.

$\dagger$ Address requests for reprints to Dr. Eugene D. Jacobson, Veterans Administration Center, Wilshire and Sawtelle Blvds., Bldg. 114, Room 231, Los Angeles, Calif. 90073.
}

mation that would not be subject to the preceding criticisms: 1) the animal must be unanesthetized and weeks past surgery; 2) both gastric secretion and blood flow must be measured simultaneously, and the measurement of one function must not interfere with measurement of the other; 3 ) frequent or continuous measurements of blood flow and secretion must be obtained for considerable periods to obviate the effect of normal fluctuations; and 4) the method of measuring blood flow must quantify gastric mucosal flow, since this can vary independently of total blood flow to the stomach.

For these reasons we selected a gastric clearance technic first described by Shore, Brodie, and Hogben (13). The method is based upon the selective permeability of lipoidal membranes to the undissociated form of compounds. Since there is a sizeable $\mathrm{pH}$ gradient from plasma to gastric juice, weakly basic drugs with a suitable pKa ( 5 to 10 ) will be transported from the plasma and will accumulate in the secretions of the stomach. The theoretical ratio $(R)$ of the concentration of these drugs in gastric juice/plasma, if we assume no limitation on the rate at which the drug is delivered to the membrane by the circulation, can be calculated from the equation,

$$
\mathrm{R}=\frac{1+10^{\mathrm{pKa}-\text { gastric juice } \mathrm{pH}}}{1+10^{\mathrm{pKa}-\text { plasma } \mathrm{pH}}} .
$$

For weak bases with pKa less than 2 , the theoretical $R$ (diffusion limited only) was identical with the observed $\mathrm{R}$. However, for aminopyrine ( $\mathrm{pKa}$ $=5$ ) the theoretical $R$ would be approximately $10^{4}$, whereas the observed $R$ was 40 , suggesting that blood flow is not infinitely fast and that it limits the transit of aminopyrine by the rate at which it delivers the drug to the membrane (13). If blood flow is a factor that limits $R$, then aminopyrine is suited as a clearance marker for estima- 
tion of mucosal blood flow and should meet the requirements of the Fick principle.

A basic assumption of the use of this clearance technic for estimating blood flow is that the mucosa completely clears the drug from the circulation on a single passage through that tissue which is exposed to acid gastric juice. This assumption cannot be tested directly, since venous blood from the stomach drains nonmucosal structures as well as the mucosa. However, as will be developed in this presentation, several considerations make this assumption acceptable.

\section{Methods}

Unanesthetized dogs. Vagally denervated gastric fundic (Heidenhain) pouches were prepared in 12 mongrel dogs of both sexes weighing from 13 to $17 \mathrm{~kg}$. No experiments were performed during the first 3 weeks after surgery. Frequent hematocrit determinations were obtained in each dog because of the depressive effects of aminopyrine on canine bone marrow (pancytopenia) (14). Two of the animals developed a profound chronic anemia after their initial exposure to aminopyrine, and these dogs were not used further. The other ten animals showed no significant alteration in hematocrit despite administration of as much as $40 \mathrm{mg}$ of aminopyrine per kg body weight during each of five separate experiments spaced over 3 months.

A typical experiment consisted of placing the dogs in a sling frame and starting a constant infusion of saline into a hind leg vein at a rate of $0.5 \mathrm{ml}$ per minute by means of a peristaltic pump. ${ }^{1}$ A loading dose $(20 \mathrm{mg}$ per $\mathrm{kg}$ ) of aminopyrine was infused over 10 minutes, and then a maintenance dose ( $5 \mathrm{mg}$ per $\mathrm{kg}$ per hour) was continued throughout the experiment to stabilize plasma aminopyrine concentrations. After 30 minutes, during which the pouch was not secreting spontaneously, a small amount of histamine $(0.1 \mathrm{mg}$ base per hour) or porcine gastrin ( $5 \mathrm{~g}$ per hour) was added to the infused material to initiate a submaximal secretory rate. After 1 hour the dose of the stimulant was doubled, followed by successive doublings of the dose each hour until the secretory rate no longer increased with increments in drug dosage (maximal response). At this point bethanechol $(0.5 \mathrm{mg})$ was infused for 1 hour, along with the maximal dose of histamine or gastrin, to induce a supramaximal secretory response (15). In some experiments a steady submaximal secretory response was maintained with histamine or gastrin, and a secretory inhibitory agent (vasopressin, epinephrine, isoproterenol, or secretin) was added to observe the effect of these agents on both secretion and clearance.

The dosages of the various agents infused were as follows: histamine phosphate (expressed as histamine base), 0.1 to $3.2 \mathrm{mg}$ per hour; porcine gastrin, prepared in this

\footnotetext{
1 Harvard Apparatus Co., Dover, Mass.
}

laboratory (16) and expressed as wet weight of mucosa extracted, 5 to $40 \mathrm{~g}$ per hour; bethanechol (Urecholine), ${ }^{2}$ $0.5 \mathrm{mg}$ per hour; vasopressin (Pitressin), $34 \mathrm{U}$ per hour; epinephrine hydrochloride (expressed as the base), 0.25 to $2.5 \mu \mathrm{g}$ per $\mathrm{kg}$ per minute; and secretin,4 $76 \mathrm{U}$ injected every 15 minutes intravenously. The dosages of the last four agents were chosen to induce inhibition of secretion without also producing undesired symptoms (collapse, retching, excitement).

Chemical determinations. Gastric juice samples from the pouch were collected every 15 minutes, and the volume was recorded and the concentration of $\mathrm{HCl}$ determined by titration with $0.2 \mathrm{~N} \mathrm{NaOH}$ to $\mathrm{pH} 7.0$ with a Radiometer autoburette. Six-ml brachial venous blood samples were aspirated into oxalated tubes at hourly intervals throughout each experiment and centrifuged; the plasma was preserved. The concentration of aminopyrine in each gastric juice and plasma sample was determined by the method of Brodie and Axelrod (17). This technic consists essentially of alkalinizing a $1-\mathrm{ml}$ biological sample, extracting aminopyrine into dichloroethane solvent, washing with sodium borate, and extracting aminopyrine back into an aqueous acid phase. The concentration of drug is then determined by its absorption at $560 \mathrm{~m} \mu$ in a Zeiss spectrophotometer. In our hands the limit of detection of aminopyrine was $1 \mu \mathrm{g}$ in a $1-\mathrm{ml}$ sample of either gastric juice or plasma. In 30 pairs of consecutive duplicate samples from our experiments, the standard deviation of the mean of paired samples was $0.6 \mu \mathrm{g}$ per ml. ${ }^{\circ}$ These results compare favorably with the limits of the method as originally described by Brodie and Axelrod (17). This method measures not only aminopyrine but also one of its metabolites, 4-amino antipyrine. In our experience, however, the concentration ratio of substances in gastric juice and plasma measured by this method remained remarkably constant under constant experimental conditions. Furthermore, Shore and co-workers (13) measured aminopyrine concentrations in gastric juice and plasma under conditions similar to our experiments and observed an $\mathrm{R}$ for aminopyrine alone that was nearly the same as the $R$ we found.

Our recoveries of aminopyrine from canine plasma and gastric juice were not significantly different from recoveries from distilled water (over 97\%), again agreeing with the original report for this method (17). Brodie and Axelrod also found that whole blood aminopyrine concentrations were $85 \%$ of the plasma value.

The clearance, which can be assumed to represent pouch mucosal plasma flow, was calculated from the relationship, $C=G V / P$, where $C$ is the clearance (milliliters per minute), $G$ and $P$ are gastric juice and plasma

2 Merck, Sharp and Dohme, Philadelphia, Pa.

3 Parke, Davis, Detroit, Mich.

4 Vitrum, Stockholm, Sweden.

5 Calculated from $\sqrt{d^{2} / 4 n}$, where $d$ is the difference between each duplicate pair of samples and $n$ is the number of pairs (18). The formulae for the coefficient of correlation and tests of significance are to be found in Snedecor's text (19). 
aminopyrine concentration (milligrams per milliliter), and $\mathrm{V}$ is the gastric secretory rate (milliliters per minute).

The ratio of $G / P$, which is designated as $R$, is of more than passing interest $(13,20,21)$. It expresses the limitation imposed by the circulation on the transit of weak base across the gastric mucosal membrane. In other words, $\mathrm{R}$ tells us how much plasma flow in the mucosa occurred per unit of secretory volume. For these reasons both clearance and $\mathrm{R}$ will be compared with gastric secretory rate in our results.

\section{Results}

\section{The gastric clearance technic}

Studies in anesthetized dogs. In two acute experiments on anesthetized dogs we found that there was no significant arteriovenous concentration difference for aminopyrine in the following circulatory areas: small intestine, brain and head, kidney, heart and lungs, and forelimb. By contrast, in seven other acute experiments the stomach cleared $58 \%$ (range, 44 to $75 \%$ ) of the aminopyrine from the blood presented to it. These determinations were made at the end of 30 minutes stimulation with histamine.

We compared the amount of aminopyrine secreted by the total stomach in 1 hour with the amount of drug cleared simultaneously from the blood perfusing the stomach (product of stomach blood flow and arteriovenous concentration differ-

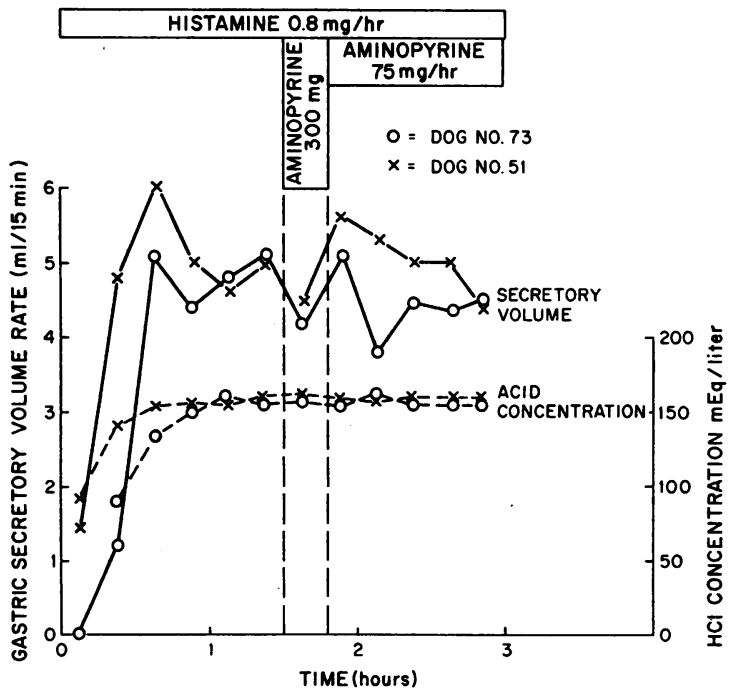

Fig. 1. ResUlts From tWo EXPERIMENTS SHOWING THAT AMINOPYRINE AS USED IN THIS STUDY HAD NO EFFECT ON EITHER THE VOLUME RATE OF SECRETION OR THE CONCENTRATION OF HCL IN GASTRIC JUICE.
TABLE I

Effect of pouch solution $\mathrm{pH}$ and histamine on the amount of aminopyrine collected from the pouch

\begin{tabular}{lc}
\hline \hline $\begin{array}{c}\mathrm{pH} \text { of recovered } \\
\text { solution }\end{array}$ & $\begin{array}{c}\text { Aminopyrine recovered } \\
\text { in } 30 \text { minutes }\end{array}$ \\
\hline & $\mathrm{mg}$ \\
0.9 & $3.3 \pm 0.8(\mathrm{SE})$ \\
1.0 & $3.7 \pm 0.7$ \\
0.5 & $0.5 \pm 0.2$ \\
0.9 (histamine) & $10.1 \pm 1.9$ \\
\hline
\end{tabular}

ence). This was performed during stimulation with histamine in two acute experiments on anesthetized dogs with isolated gastric circulation (22). In each experiment over $90 \%$ of the extracted aminopyrine was recovered in the gastric juice.

Studies in unanesthetized dogs. Aminopyrine as used in our experiments did not affect gastric secretion. In two dogs (Figure 1) a stable secretory rate was established with histamine, and the infusion of aminopyrine did not alter either the volume rate of secretion or the acid concentration of gastric juice.

When a constant stimulus to gastric secretion was used and a constant amount of aminopyrine infused to maintain stable plasma concentrations, we observed no significant changes in $R$ values over many hours. This relative constancy of $R$ was noted not only when gastric secretions were allowed to drain freely to the exterior but also when pouch secretions were kept in constant contact with the mucosa. This steady state for $\mathrm{R}$ suggested that reabsorption of aminopyrine from the pouch must be minimal. This possibility was investigated in 22 experimental periods of $30 \mathrm{~min}$ utes each in three different animals. We kept a $50-\mathrm{ml}$ solution containing $1 \mathrm{mg}$ per $\mathrm{ml}$ aminopyrine in $0.1 \mathrm{~N} \mathrm{HCl}$ (this corresponds to the concentrations of aminopyrine and $\mathrm{HCl}$ secreted during our experiments) in contact with the pouch mucosa during each of the experimental periods. Recovery of aminopyrine from pouch solutions in these 22 periods was $96 \pm 1 \%$ (SE) of that instilled, which was not significantly different from $100 \%$ ( $\mathrm{p}>0.1$ ).

The effect of varying the $\mathrm{pH}$ of the pouch solution on aminopyrine clearance was examined during seven experiments on six animals. A constant dose of aminopyrine was administered throughout each experiment, and the different solutions were 


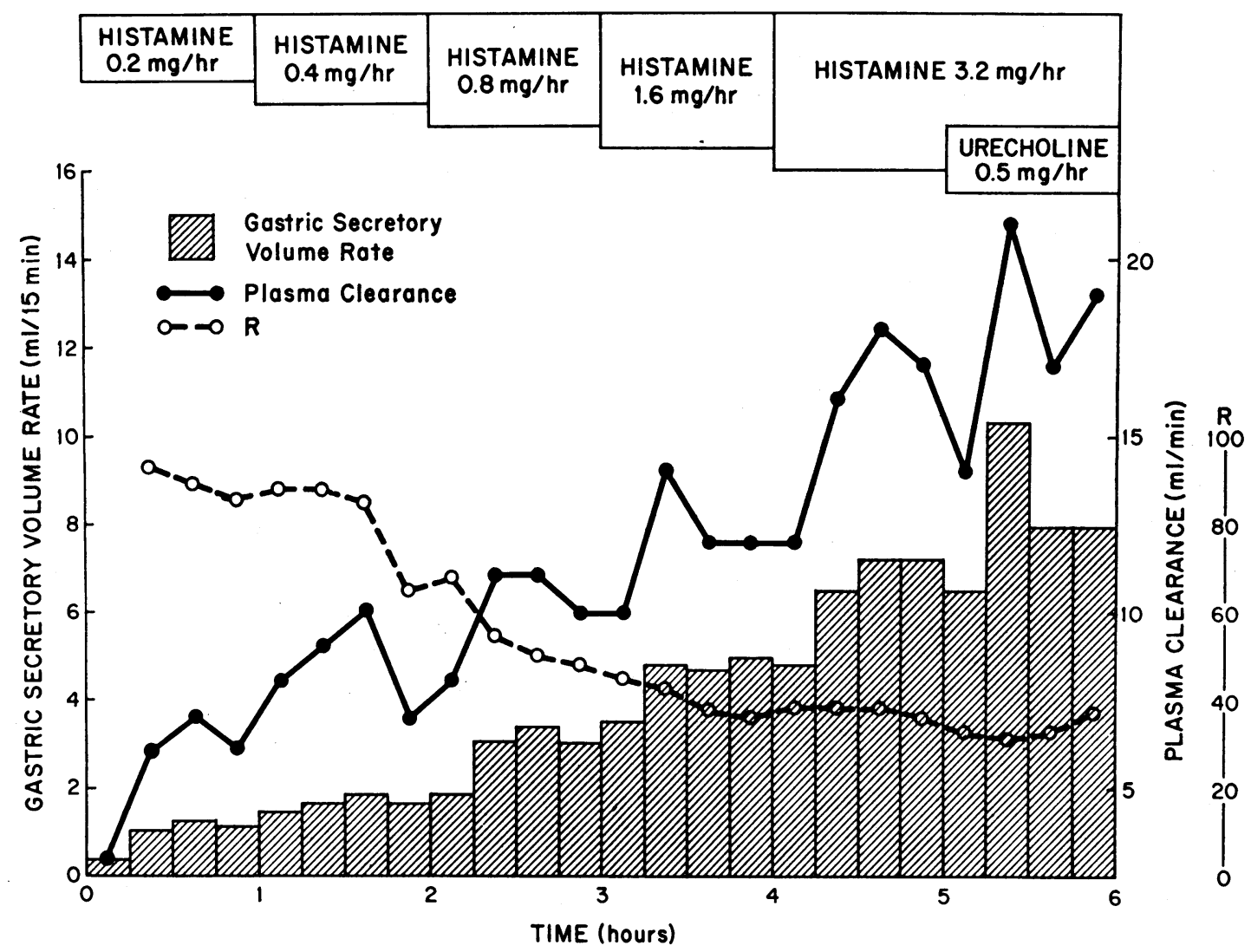

Fig. 2. EFFeCtS OF HistaMine IN PROGRESSIVELy INCREASING DOSES ANd URECholine ON GASTRIC SECRETORY RATE, MUCOSAL CLEARANCE, AND $R$ IN ONE EXPERIMENT. $R=$ the ratio of gastric juice/plasma aminopyrine concentrations.

kept in contact with the pouch mucosa by means of a reservoir. It can be seen from the results of these experiments in Table I that there was little difference between the amount of aminopyrine crossing into the pouch filled with solutions at low $\mathrm{pH}(1.0$ or 0.9$)$, but the alkaline solution $(\mathrm{pH}$ 8.4) contained very little drug. By contrast, histamine induced a marked increase in aminopyrine clearance despite the fact that the $\mathrm{pH}$ of the secreted juice was also 0.9. Apparently the amount of aminopyrine accumulating in the pouch depends upon at least two major factors: the presence of an acid gradient from plasma to gastric juice, and a mucosal factor, about which we shall present evidence and which we believe is the rate at which the gastric mucosal circulation can deliver aminopyrine to the membrane for transport.

An effort was made to maintain plasma aminopyrine concentrations at a steady level in each experiment. In a few experiments, however, con- siderable fluctuation in plasma concentrations was noted, and this afforded us the opportunity to observe its effect on $\mathrm{R}$. In two animals plasma aminopyrine concentrations varied 43 and $53 \%$, respectively, from initial values during each experiment; $\mathrm{R}$ values in these same studies varied 12 and $15 \%$, and there was no directional correlation between changes in concentration and changes in R. Furthermore, in the many experiments reported in our study, although plasma aminopyrine concentrations varied between experiments over the range 15 to $53 \mu \mathrm{g}$ per ml, at maximal secretory rates nearly all $R$ values fell in the range 30 to 40 . These findings suggest that in our experiments maximal transport ( $\mathrm{Tm}$ ) was not reached for the secretion of aminopyrine by the stomach, since increments in the concentration beyond that required to achieve Tm would be associated with a progressive decline in R. Finally, the constancy of $\mathrm{R}$ during brisk secretion in the face of widely 
fluctuating plasma aminopyrine concentrations indicates a fairly constant extraction ratio across the gastric mucosa.

\section{The relationship between secretion and blood flow}

Histamine. Dose-response experiments with histamine demonstrated the anticipated effect on gastric secretion in six dogs with denervated pouches. Successive doubling of the dose infused caused a corresponding increment in the secretory rate that could be increased further by the addition of bethanechol (Figure 2). Coincident with the increase in gastric secretory rate, there was an increase in the clearance value. The ratio (R) of gastric juice to plasma aminopyrine concentrations exhibited a decline from high values at low secretory rates to a steady plateau value of 30 to 40 at near maximal or supramaximal secretory rates.

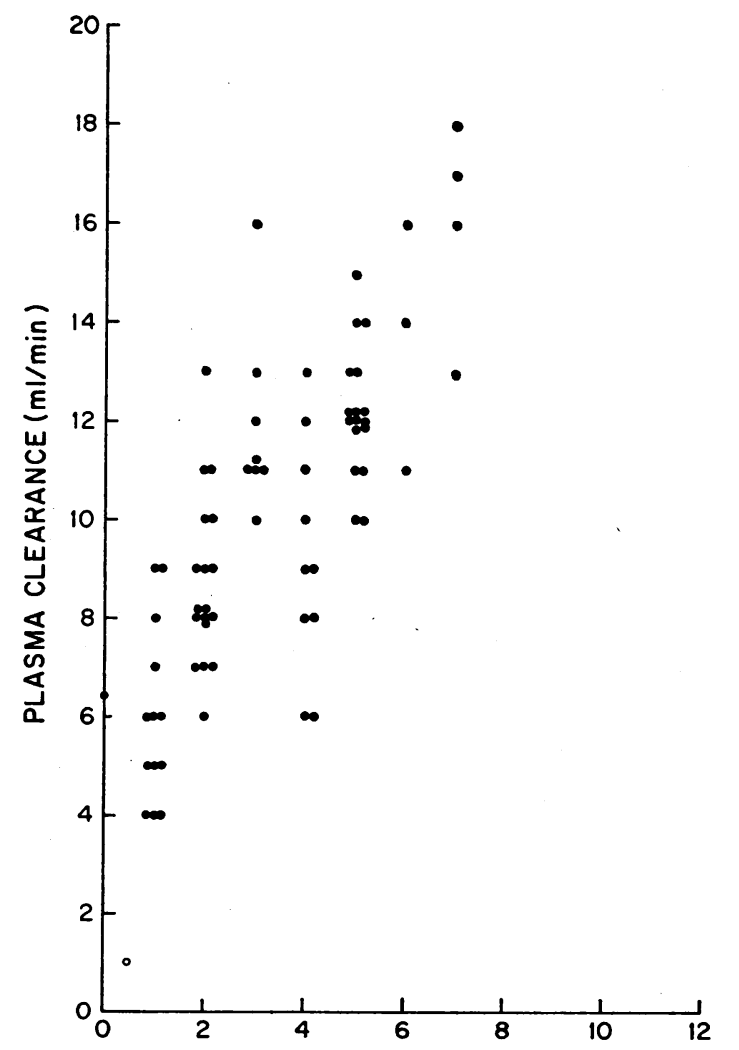

GASTRIC SECRETORY VOLUME RATE $(\mathrm{ml} / 15 \mathrm{~min})$

Fig. 3. Plot of Secretory rate against clearance FOR SIX EXPERIMENTS IN WHICH HISTAMINE WAS EMPLOYED.

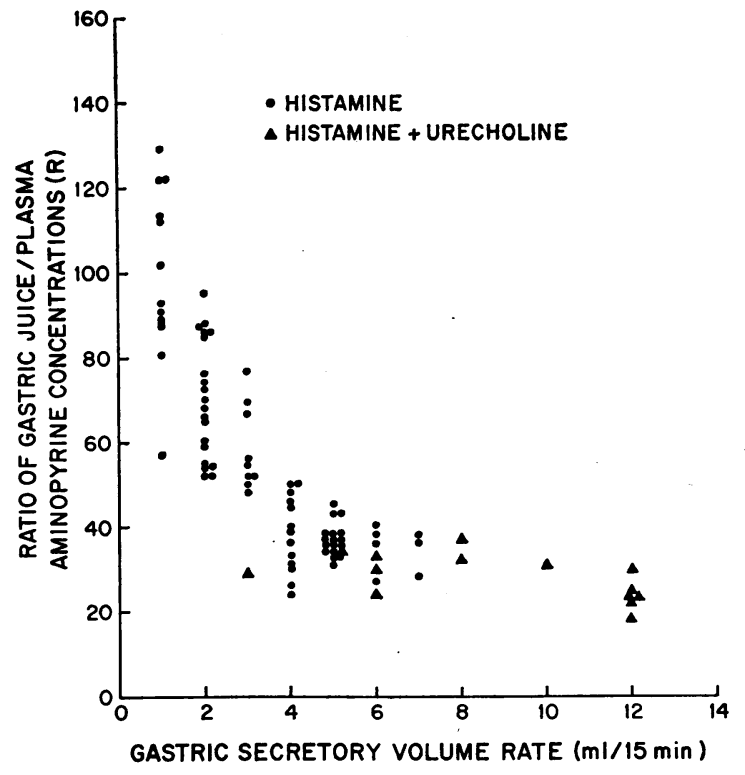

Fig. 4. R PLOTTEd AS A FUNCTION OF SECRETORY RATE IN EXPERIMENTS IN WHICH HISTAMINE AND URECHOLINE WERE USED.

Concentration of $\mathrm{HCl}$ in gastric juice did not vary greatly in our experiments. At all but the lowest secretory rates $\mathrm{HCl}$ concentration was 148 to $163 \mathrm{mEq}$ per $\mathrm{L}$ during stimulation with histamine and 133 to $164 \mathrm{mEq}$ per $\mathrm{L}$ with gastrin. Therefore, the output of acid was almost a linear function of the volume rate of secretion of gastric juice, and the relation between acid output and plasma clearance was of the same form as the relation between the volume rate of secretion and clearance.

A graphic comparison of gastric secretory volume rate and plasma clearance in the six experiments of this type is shown in Figure 3. It can be seen that secretion and clearance exhibit a significant positive correlation $(r=0.95, p<0.01)$ over the range of minimal to maximal secretory response to histamine.

A comparison of secretory rates and $R$ in the same experiments (Figure 4) again demonstrates the high $R$ values at low secretory rates, the decline in $R$ as secretion increases, and the plateau of $R$ in the neighborhood of 30 as maximal and supramaximal secretory rates are achieved in the pouch.

Gastrin. Simultaneous gastric secretory a.1d circulatory responses to different doses of gastrin 


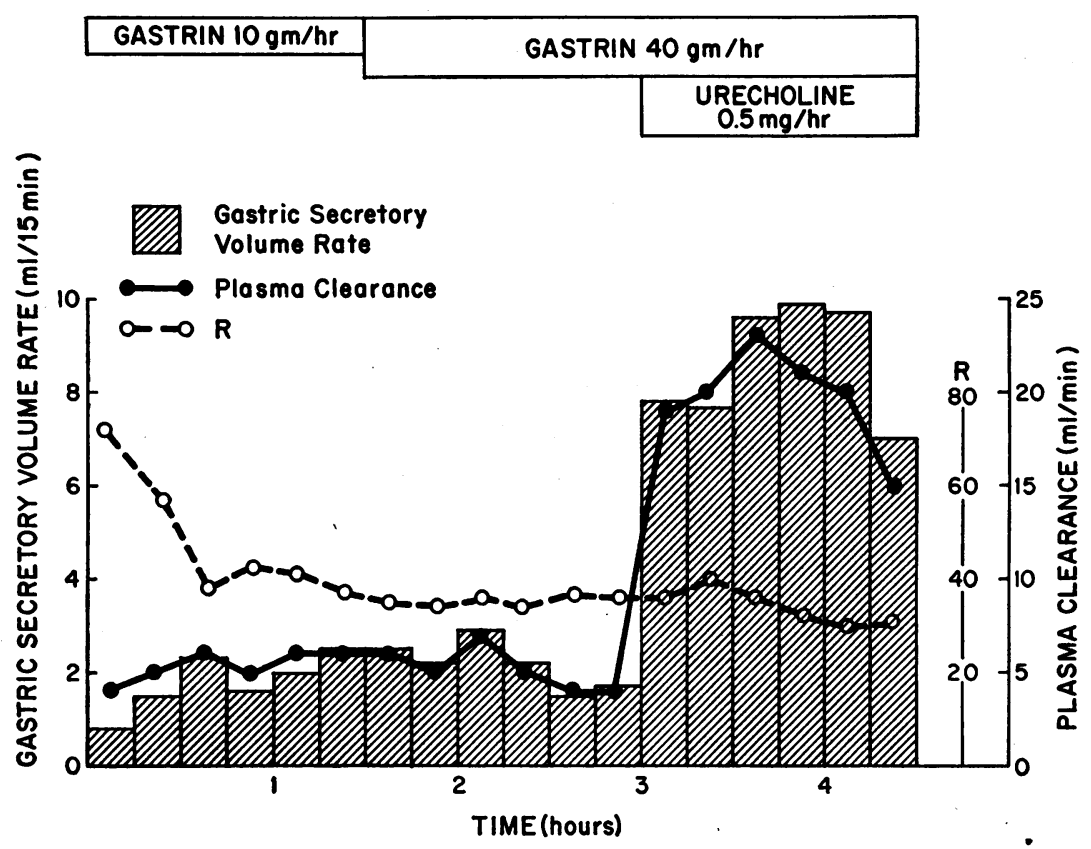

Fig. 5. RESPONSES OF SECRETORY RATE, CLEARANCE, AND R TO GASTRIN AND URECHOLINE IN ONE EXPERIMENT.

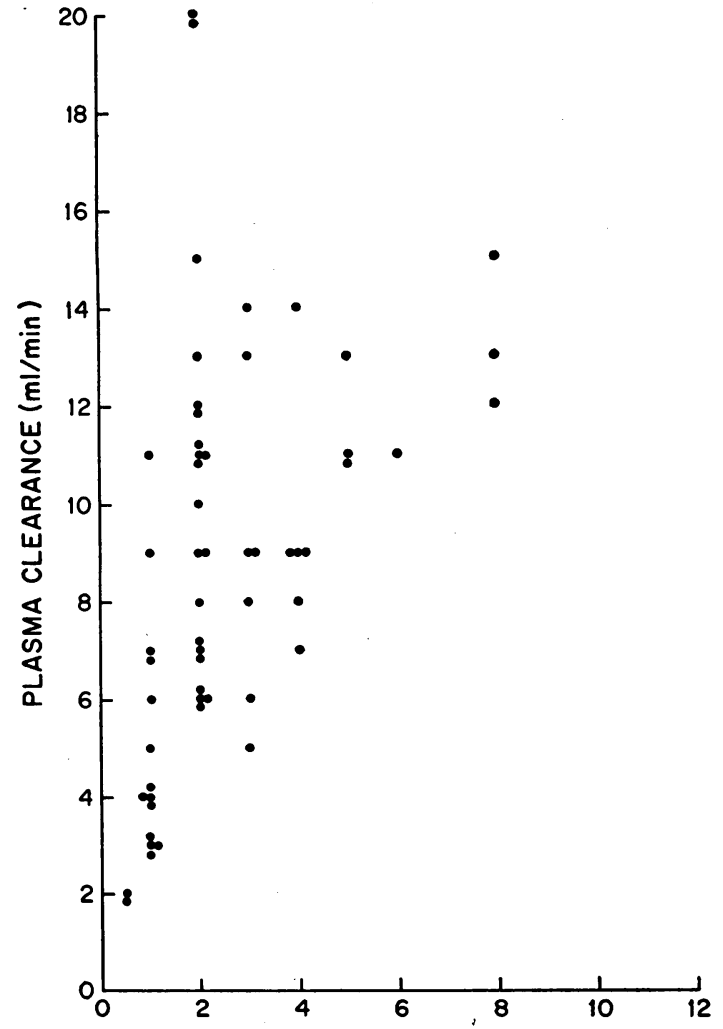

GASTRIC SECRETORY VOLUME RATE ( $\mathrm{ml} / 15 \mathrm{~min})$

Fig. 6. Mucosal clearance as a function of SeCreTORY RATE IN SIX EXPERIMENTS USING GASTRIN TO STIMULATE SECRETION. and to gastrin and bethanechol in one animal are shown in Figure 5. The maximal secretory response to gastrin was attained at a dosage of $10 \mathrm{~g}$ per hour; no further secretory increment was observed when $40 \mathrm{~g}$ per hour was administered; however, addition of bethanechol to gastrin induced a supramaximal secretory response. The changes of mucosal blood flow, as estimated by the clearance, corresponded quite well to the changes in secretion, both in direction and magnitude. $\mathrm{R}$ showed a decrease as secretion was increasing from low levels and then remained fairly steady at 30 to 40 throughout the remainder of the experiment.

Graphic comparison of secretory volume rate and plasma clearance in six experiments with gastrin is shown in Figure 6. The scatter is somewhat greater than for histamine $(r=0.85, \mathrm{p}<$ $0.01)$. However, as with histamine, when secretory rate increased, clearance increased.

A plot of $R$ as a function of secretory rate for all gastrin experiments reveals, as with histamine, the same rapid decay in $R$ as secretory rate rose from minimal values with a plateau at 30 to 40 in the maximal and supramaximal secretory range (Figure 7).

Gastric secretory inhibitors. a) Vasopressin. The effect of vasopressin on gastric secretion, mu- 
cosal plasma clearance, and $\mathrm{R}$ during background stimulation with a fixed dose of histamine was observed in three animals, and results from one experiment are shown in Figure 8. The expected inhibition of secretion induced by the administration of vasopressin was associated with a parallel decline in clearance and a slight rise in R. After cessation of the vasopressin, secretion and mucosal blood flow increased, whereas $\mathrm{R}$ exhibited a return toward prevasopressin values.

A plot of secretion versus clearance in the experimental periods during which vasopressin and histamine were administered together is shown in Figure 9. Since vasopressin inhibited secretion so effectively, the range of values is restricted to low secretory and blood flow rates. Nevertheless, comparison of these values with similar secretoryclearance points during administration of histamine alone (Figure 3) reveals little overlap between groups. With vasopressin and histamine higher secretory rates were associated with an increased blood flow $(\mathrm{r}=0.95, \mathrm{p}<0.01)$.

b) Isoproterenol. Inhibition by isoproterenol of submaximal gastric secretory rates maintained with infusion of histamine was investigated in seven animals. Results from one experiment using two doses of the sympathomimetic dilator appear in Figure 10. At the lower dose the drug did

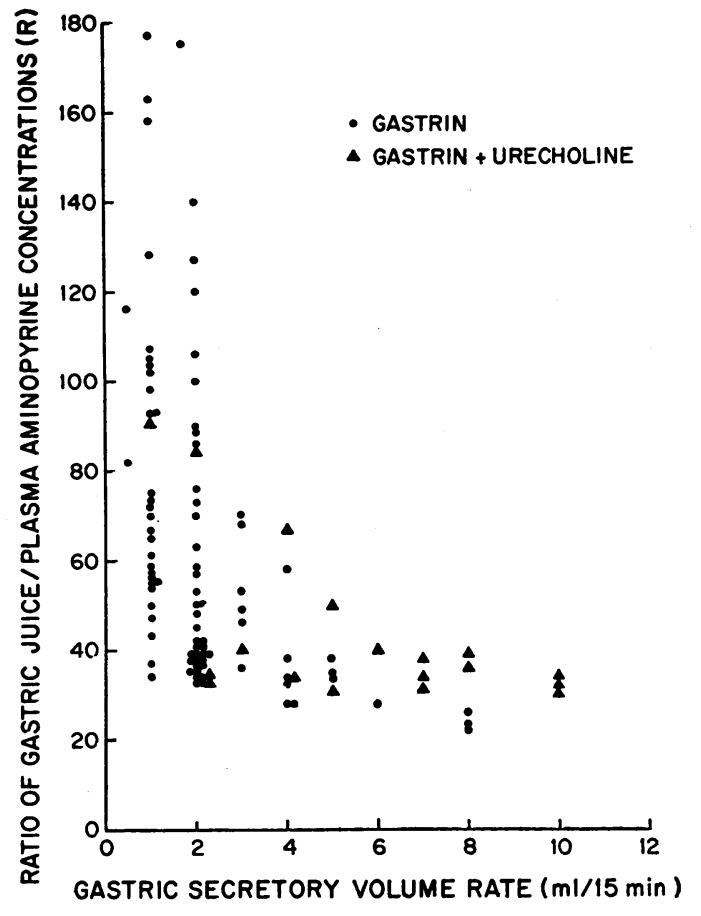

Fig. 7. R PLOTTED AS A FUNCTION OF SECRETORY RATE IN EXPERIMENTS USING GASTRIN ALONE OR IN COMBINATION WITH URECHOLINE.

not depress secretion, and the clearance was markedly increased. With the higher dose both secretion and clearance declined; whereas secretion fell

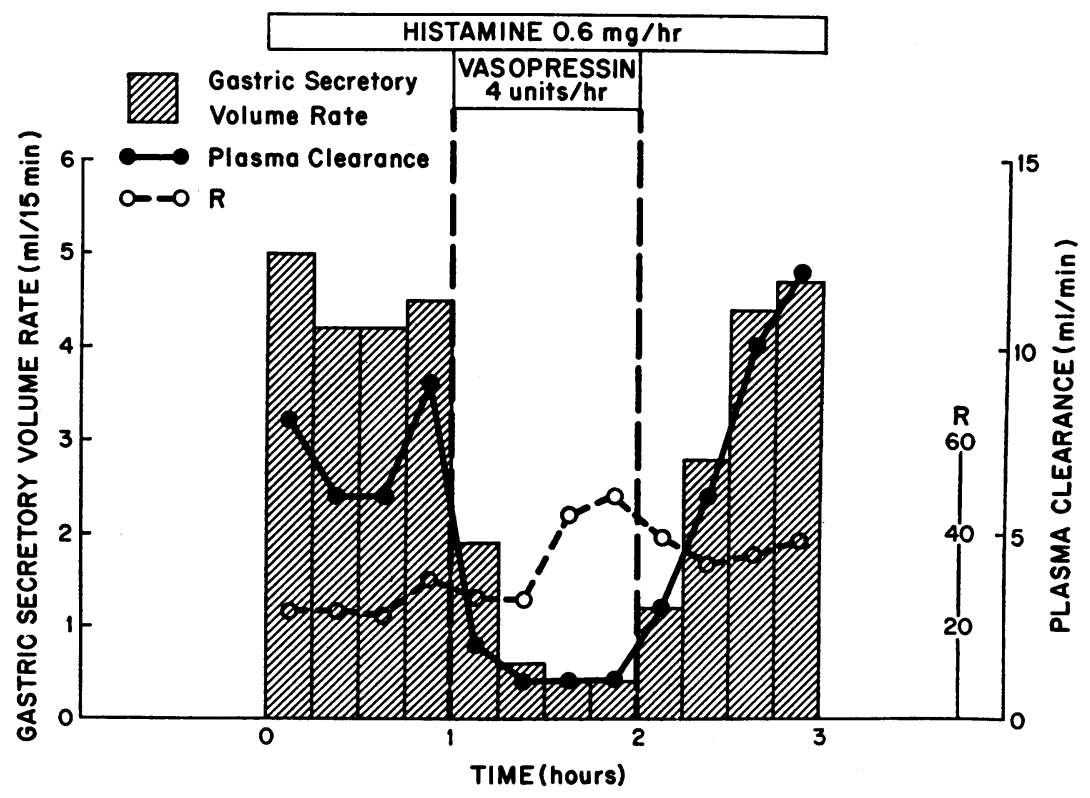

Fig. 8. INHIBITION OF BOTH SECRETION AND MUCOSAL CLEARANCE BY VASOPRESSIN DURING STIMULATION WITH HISTAMINE. 


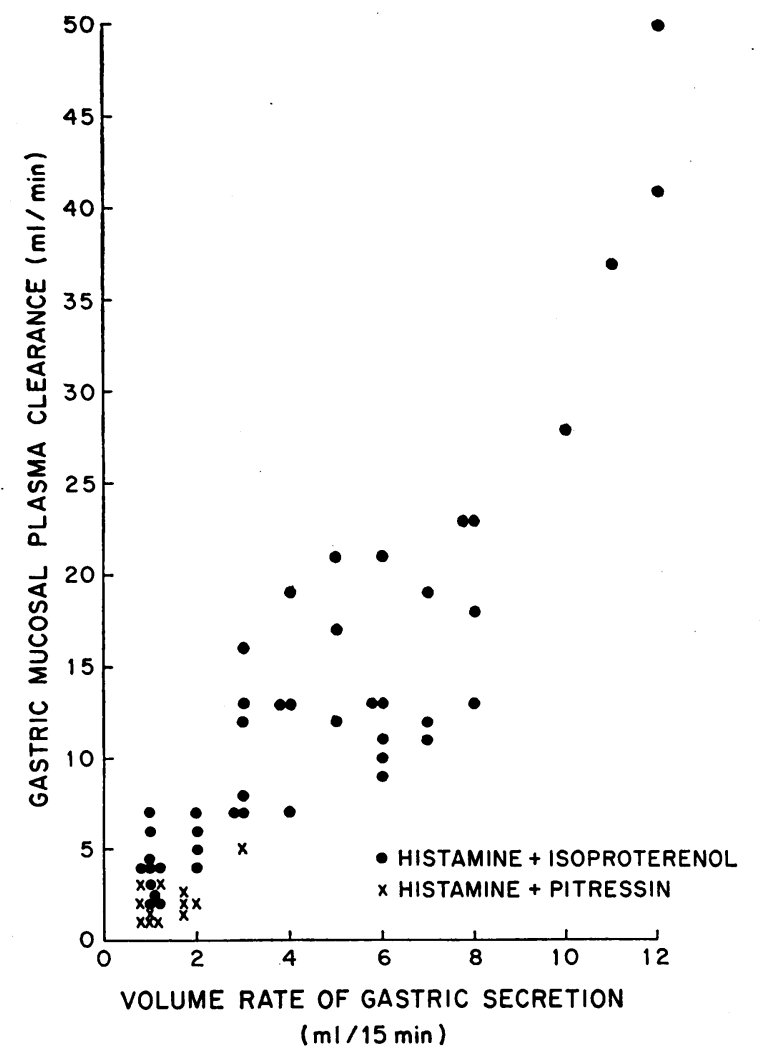

Fig. 9. Mucosal Clearance as a function of SeCreTORY RATE DURING INHIBITION OF HISTAMINE-STIMULATED SeCretion by Pitressin oR isoproterenol. well below preisoproterenol values, clearance was approximately reduced to preisoproterenol values. Thus, the clearance diminished less than secretion in response to the higher dose of isoproterenol; however, during the preceding period when the lower dose was used, the clearance was high relative to the rate of secretion. After withdrawal of isoproterenol, both secretion and clearance increased, with secretion not reaching control values and mucosal plasma flow exceeding control levels. $\mathrm{R}$ was abruptly increased from the control plateau by isoproterenol, and the progressive increase in $R$ continued long after cessation of infusion of dilator catecholamine. Results in the other six experiments were similar, i.e., isoproterenol could increase clearance without altering secretory rate; once secretion was inhibited, however, clearance also decreased from values obtained when secretion was not affected by isoproterenol.

A plot of values for secretion versus clearance during the periods when isoproterenol and histamine were administered together is shown in Figure 9. For this drug combination, as with all preceding agents, secretory rate changes were associated with clearance changes in the same direction $(\mathrm{r}=0.98, \mathrm{p}<0.01)$.

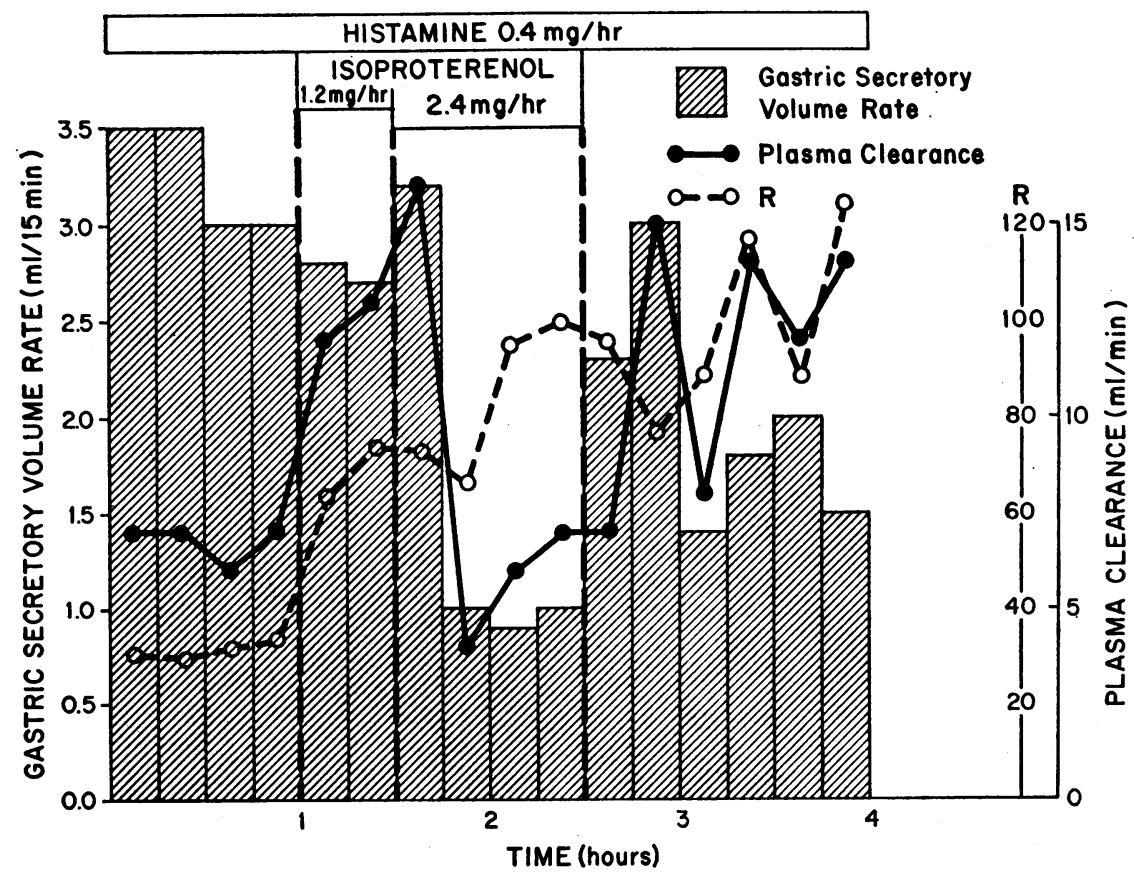

Fig. 10. Responses of SECRETION, CleARANCE, ANd R to Histamine ALONE ANd in COMBINATION WITH TWO DOSES OF ISOPROTERENOL, ONE OF WHICH INHIBITED SECRETION. 


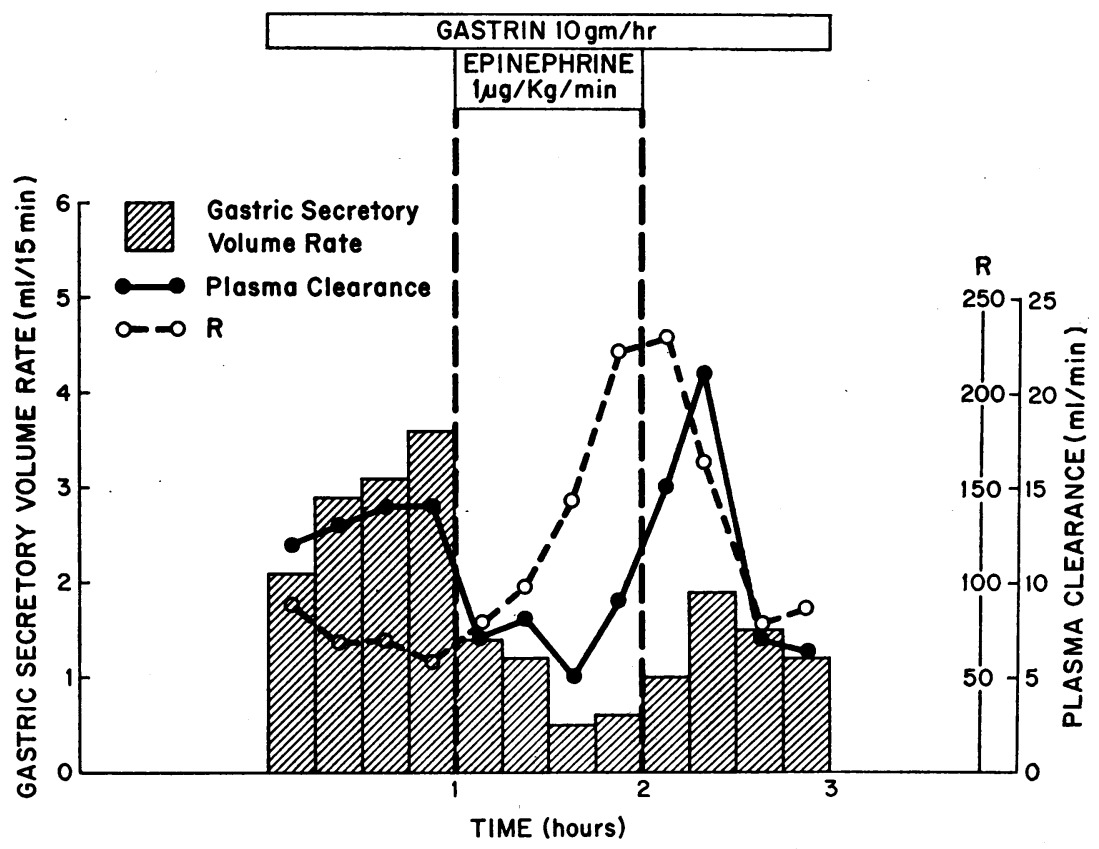

Fig. 11. RESPONSES OF SECRETORY RATE, CLEARANCE, AND R DURING INHIBITION OF GASTRIN-STIMULATED SECRETION BY EPINEPHRINE.

c) Epinephrine. The effects of epinephrine (during background stimulation with gastrin) on gastric secretion, clearance, and $\mathrm{R}$ were observed in three dogs. Typical results (Figure 11) were an inhibition of both secretion and clearance and an increase in $\mathrm{R}$ during the interval of epinephrine infusion, and a return toward precatecholamine values after cessation of epinephrine. The scatter of values for secretion versus clearance during experimental periods when the two drugs were delivered together is shown in Figure 12. Changes in secretory rate were associated with directionally corresponding changes in clearance $(r=0.94, p<$ 0.01 ).

d) Secretin. The action of secretin on gastric secretion, clearance, and $\mathrm{R}$ was observed in three animals, and results from one experiment appear in Figure 13. The hormone inhibited secretion and clearance and induced a rise in $R$. These effects were not entirely gone 1 hour after the last secretin injection. Results from these three experiments (Figure 12) demonstrate that during periods of administration of both secretin and gastrin changes in secretion correlated well with changes in clearance $(r=0.93, p<0.01)$.

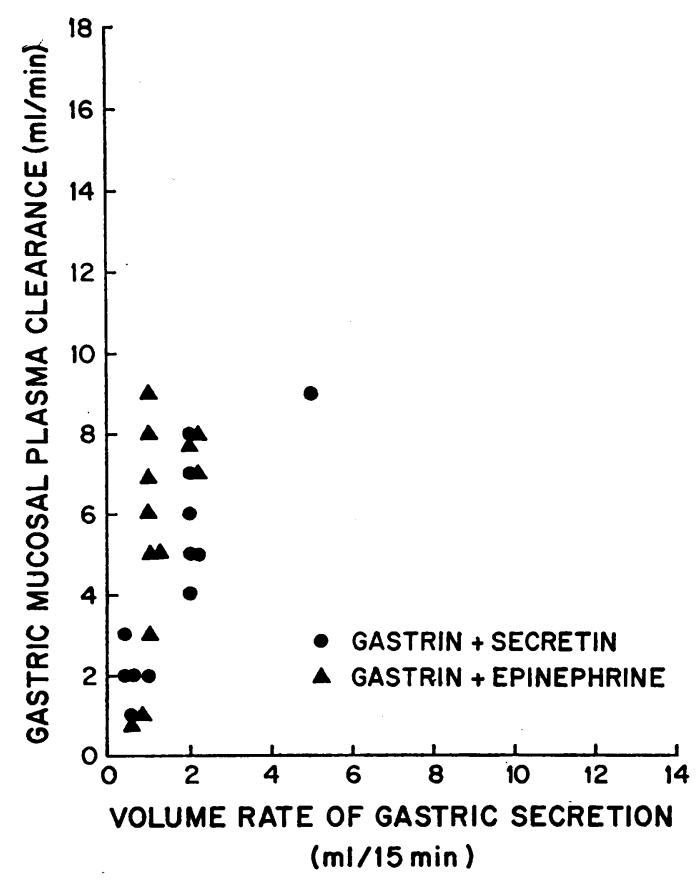

Fig. 12. Clearance plotted as a function of secreTORY RATE DURING INHIBITION OF GASTRIN-STIMULATED SECRETION BY EPINEPHRINE OR SECRETIN. 


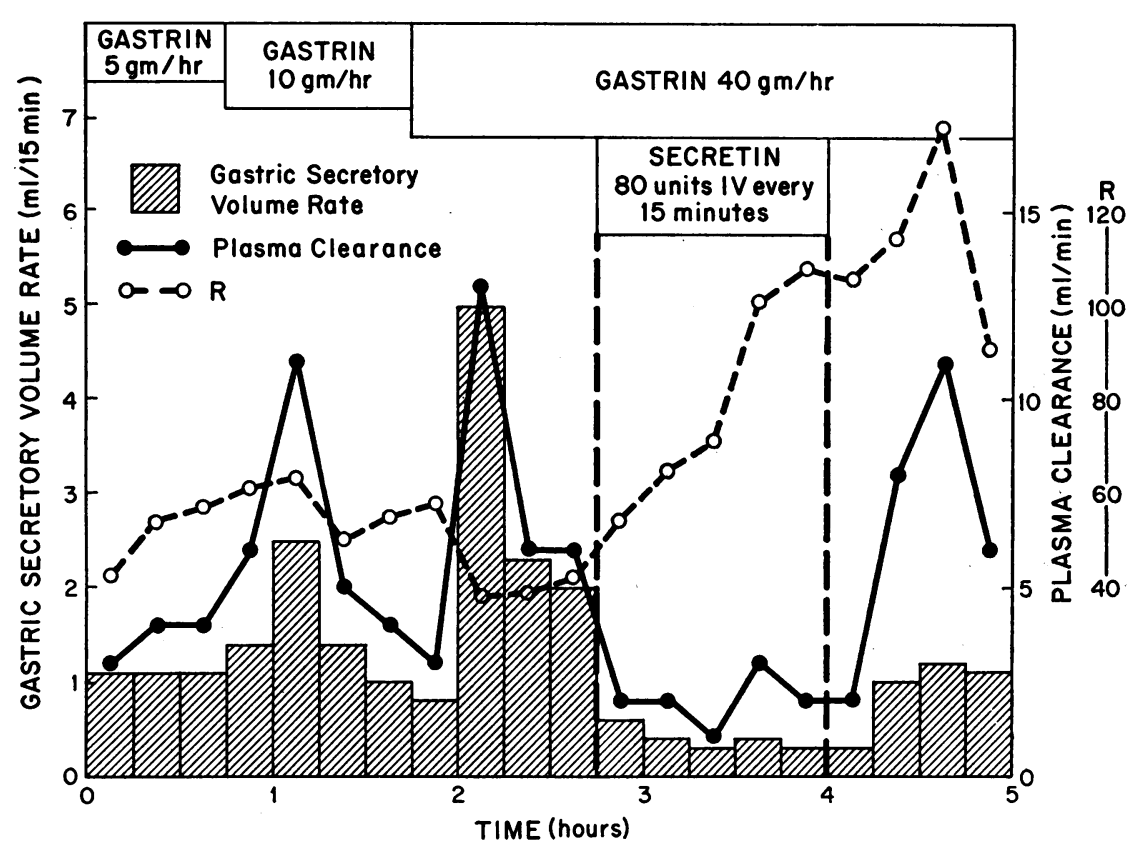

Fig. 13. RESPONSES OF SECRETORY RATE, CLEARANCE, AND R DURING INHIBITION OF GASTRIN-STIMULATED SECRETION BY SECRETIN.

\section{Discussion}

The findings of our study indicate that secretion and blood flow are related in the stomach. There are, however, other reports that present evidence against such a relationship, namely that known secretory stimuli did not increase gastric blood flow and known inhibitors of secretion failed to decrease blood flow to the stomach (7-11). In four of these reports $(7-10)$ anesthetized and even hypotensive animals were used, which may account for some of the discrepancies among these papers: histamine was observed to increase (11), to decrease (8), and not to alter gastric blood flow $(7,10)$; epinephrine was found to increase $(10$, $11)$ and to decrease $(7,8)$ blood flow to the stomach. Only the investigation by Delaney and Grim (11) was conducted on unanesthetized dogs, and they performed no secretory studies. Thus, their finding that secretin and epinephrine (secretory inhibitors) did not diminish gastric blood flow is of questionable value, since these drugs were employed in the unstimulated stomach. Finally, Harries (23) demonstrated that isoproterenol decreased gastric secretion, which, he maintained, disproved a relationship between secretion and blood flow, since isoproterenol is a splanchnic vaso- dilator. Harries did not, however, measure the effect of isoproterenol on gastric blood flow.

Our results strongly support a positive relationship between gastric secretion and blood flow. In a large number of experiments with seven different drugs that affect gastric secretion, we consistently observed this relationship: as gastric secretion changed, gastric mucosal blood flow (as estimated by clearance) changed correspondingly. Results with the stimulatory agents histamine, gastrin, and bethanechol appear to us to be the most clear-cut; dose-response relationships obtained about as well for clearance as for secretory rate. In the experiments with gastric secretory inhibitors, results were more complex, as for example the different effects of vasopressin and isoproterenol on $\mathrm{R}$ when both agents depressed secretion and clearance. The results from these inhibitory experiments, however, still support a positive correlation between secretion and blood flow (Figures 9 and 12).

The ratio $(R)$ of gastric juice to plasma aminopyrine concentrations declined to a plateau value in the range of 30 to 40 when secretion achieved moderate to maximal rates, but was considerably higher than 40 when small doses of histamine or 
gastrin were employed. This plateau value for aminopyrine is similar to what Shore and his associates (13) reported with a maximal stimulatory dose of histamine. We also noted that during inhibition of secretion, especially with the catecholamines and secretin, $\mathrm{R}$ became markedly elevated. We have interpreted $\mathrm{R}$ as an indicator of the limitation imposed by the circulation on the transit of poorly ionized drugs across the stomach. $\mathrm{R}$ may be interpreted further as the number of unit volumes of mucosal blood that have flowed during the formation of one unit volume of secretion under a given set of conditions. Thus, a high $\mathrm{R}$ indicates that blood flow is disproportionately high in relation to secretion, a condition seen at low secretory rates with low doses of stimulants, or with secretory inhibitors (e.g., secretin, catecholamines) that do not limit blood flow, or with an agent that vasodilates without inhibiting secretion (low dose of isoproterenol in Figure 10). At high secretory rates induced by high doses of stimulants, $R$ declines to a fixed plateau value, probably representing the situation in which secretion is blood flow limited, and further increments in secretory rate will require 30 to $40 \mathrm{ml}$ blood flow for each $\mathrm{ml}$ of gastric juice that will be secreted.

If our inference that secretion and mucosal blood flow are normally related is valid, the next consideration is one of assessing whether secretory changes determine blood flow or the reverse. Our evidence does not allow a definitive answer to the nature of the secretory-circulatory relationship in the stomach; however, from our experiments with isoproterenol (Figure 10), it seems that blood flow can increase significantly without a corresponding increment in secretion. On the other hand, we have not observed significant secretory changes without corresponding directional changes in clearance. Secretion and blood flow in the stomach appear to be related in two major ways: 1) secretory changes determine directionally corresponding changes in the gastric mucosal circulation, and 2) various conditions of stimulation and inhibition can act to alter the amount of blood flow associated with a unit volume of secretion. In other words, it appears as if secretory changes induce corresponding circulatory alterations, but the reverse relationship, that is, alteration of secretion by a change in blood flow, is seen only when blood flow is reduced to a limiting value.
The major assumption of this clearance technic, namely that extraction is high and stable, remains to be proved. The extraction ratio for aminopyrine cannot be determined directly because pure gastric mucosal venous blood cannot be sampled. If the extraction ratio for aminopyrine varied greatly with different experimental conditions, then the clearance of aminopyrine would not be a valid method for measuring gastric mucosal blood flow, and the subscripts $\mathrm{t}, \mathrm{m}$, and $\mathrm{nm}$ represent togastric extraction of aminopyrine was $58 \%$. Using this value we can relate extraction to flow in the stomach, as $E_{t}=(E m F m+E n m F n m) /$ $(F m+F n m)$, where $E$ is extraction, $F$ is plasma flow, and the subscripts $\mathrm{t}, \mathrm{m}$, and $\mathrm{nm}$ represent total, mucosal, and nonmucosal, respectively. If we assume that nonmucosal gastric tissue does not extract aminopyrine, then it follows that with an observed Et of $58 \%$, either $\mathrm{Em}$ is $100 \%$ (or close to it), or Fnm is extremely low. Thus, if Em were $100 \%$, Fnm would be $42 \%$ of total gastric blood flow. This partition of blood flow between mucosa and nonmucosa seems reasonable, since the mucosa is about half the stomach mass. Furthermore, this distribution agrees well with distribution figures reported by Delaney and Grim (24) using ${ }^{42} \mathrm{~K}$ uptake and by Shore and his colleagues (13) employing the clearance of aniline and is close to the estimate made by Mall (25) on anatomical grounds. In any event, if this analysis is correct, Em cannot vary beyond the range of 58 to $100 \%$.

In our experiments the ratio of gastric juice to plasma aminopyrine concentrations (R) was found to vary from 20 to 175 (Figures 4 and 7). This eightfold range of $R$ values, and the even larger range of mucosal blood flow values could be explained on the basis of a variation in the relationship between mucosal blood flow and secretion or a variation in extraction ratio. As the preceding discussion indicates, an eightfold variation in extraction ratio is not possible.

It is possible that aminopyrine is actively secreted by the gastric mucosa. Our finding that stimulation of gastric secretion increases the amount of aminopyrine accumulating in the lumen of the stomach would support this possibility. The data appear at face value to show that secretory rate and clearance are inseparable. If this possibility were correct, a corollary would be that the gastric mucosa presents high resistance to pas- 
sive diffusion, clears aminopyrine incompletely from the blood, and accomplishes this clearance mainly by active transport. This alternative explanation cannot be refuted directly; however, the diversity of chemical compounds that can be concentrated by the stomach makes it unlikely that there is an active transport mechanism involving specific chemical reactions (13). Furthermore, we have found that altering the $\mathrm{pH}$ of solutions instilled into the pouch lumen markedly changes the amount of aminopyrine that will cross from blood to lumen in the nonsecreting stomach. Our experiments with low doses of isoproterenol (Figure 10) show one situation, at least, in which clearance can be raised without increasing secretion. Finally, as we have discussed previously, clearance from the mucosa cannot be far from complete.

\section{Summary}

The relationship between secretion and mucosal blood flow was investigated in the stomach of unanesthetized dogs provided with denervated pouches. Gastric mucosal blood flow was estimated by aminopyrine clearance.

Secretion and mucosal blood flow were studied during administration of varying amounts of histamine or porcine gastrin, and of combinations of these stimuli with bethanechol, vasopressin, isoproterenol, epinephrine, or secretin. Under all conditions of stimulation and inhibition, clearance varied directly with secretory rate; however, for some situations (e.g., isoproterenol plus histamine) mucosal blood flow per unit of secretion was higher than for other situations (e.g., vasopressin plus histamine). From these findings we conclude that secretion and mucosal blood flow are related in the stomach.

\section{Acknowledgments}

The authors gratefully acknowledge the technical assistance of Messrs. William Day, Alvin Chang, and Andrew Billings.

\section{References}

1. Cutting, W. C., E. C. Dodds, R. L. Noble, and P. C. Williams. Pituitary control of alimentary blood flow and secretion. The effect of alterations in blood flow on gastric secretion. Proc. roy. Soc. B 1937, 123, 39.
2. Wolf, S., and H. G. Wolff. Human Gastric Function. An Experimental Study of a Man and His Stomach. London, Oxford University Press, 1943, chap. III and IV.

3. Thompson, J. E., and J. R. Vane. Gastric secretion induced by histamine and its relationship to the rate of blood flow. J. Physiol. (Lond.) 1953, 121, 433.

4. Peters, R. M., and N. A. Womack. Hemodynamics of gastric secretion. Ann. Surg. 1958, 148, 537.

5. Jacobson, E. D., J. B. Scott, and E. D. Frohlich. Hemodynamics of the stomach. II. Relation between gastric secretion and blood flow. Amer. J. dig. Dis. 1962, 7, 786.

6. Peter, E. T., D. M. Nicoloff, H. Sosin, A. I. Walder, and O. H. Wangensteen. Relationship between gastric blood flow and secretion. Fed. Proc. 1962, 21, 264.

7. Lim, R. K. S., H. Necheles, and T. G. Ni. The vasomotor reactions of the (vivi-perfused) stomach. Chin. J. Physiol. 1927, 1, 381.

8. Böenheim, F. Über das Minutenvolumen des Magens und seine Beeinflüssung durch Blutdruck, durch Vagusreizung, durch Histamin und durch Organextracts. Z. ges. exp. Med. 1930, 71, 88.

9. Necheles, H., P. Levitsky, R. Kohn, M. Maskin, and R. Frank. The vasomotor effect of acetylcholine on the stomach of the dog. Amer. J. Physiol. 1936, 116, 330.

10. Cumming, J. D., A. L. Haigh, E. H. L. Harries, and M. E. Nutt. A study of gastric secretion and blood flow in the unanesthetized dog. J. Physiol. (Lond.) 1963, 168, 219.

11. Delaney, J. P., and E. Grim. Experimentally induced variations in canine gastric blood flow and its distribution. Amer. J. Physiol. 1965, 208, 353.

12. Jacobson, E. D. The circulation of the stomach. Gastroenterology 1965, 48, 85.

13. Shore, P. A., B. B. Brodie, and C. A. M. Hogben. The gastric secretion of drugs: a $\mathrm{pH}$ partition hypothesis. J. Pharmacol. exp. Ther. 1957, 119, 361.

14. Butt, E. M., A. M. Hoffman, and S. N. Soll. Experimental production of neutropenia with aminopyrine. Arch. intern. Med. 1939, 64, 26.

15. Gillespie, I. E., and M. I. Grossman. Potentiation between Urecholine and gastrin extract and between Urecholine and histamine in the stimulation of Heidenhain pouches. Gut 1964, 5, 71 .

16. Gregory, R. A., and H. J. Tracy. The constitution and properties of two gastrins extracted from hog antral mucosa. I. The isolation of two gastrins from hog antral mucosa. Gut 1964, 5, 103.

17. Brodie, B. B., and J. Axelrod. The fate of aminopyrine (Pyramidon) in man and methods for the estimation of aminopyrine and its metabolites in biological material. J. Pharmacol. exp. Ther. 1950, 99, 171.

18. Youden, W. J. Statistical Methods for Chemists. New York, John Wiley, 1951, p. 16. 
19. Snedecor, G. W. Statistical Methods Applied to Experiments in Agriculture and Biology, 5th ed. Ames, Iowa State College Press, 1956, pp. 46, 158.

20. Milne, M. D., B. H. Scribner, and M. A. Crawford. Nonionic diffusion and excretion of weak acids and bases. Amer. J. Med. 1958, 24, 709.

21. Van Os, G. A. J., E. J. Ariens, and A: M. Simonis. Drug transference: distribution of drugs in the organism in Molecular Pharmacology, E. J. Ariens, Ed. New York, Academic Press, 1964, vol. 1, pp. 12-14.
22. Jacobson, E. D., E. S. Dooley, J. B. Scott, and E. D. Frohlich. Effects of endotoxin on the hemodynamics of the stomach. J. clin. Invest. 1963, 42, 391.

23. Harries, E. H. L. The mode of action of sympathomimetic amines in inhibiting gastric secretion. J. Physiol. (Lond.) 1957, 138, 48 P.

24. Delaney, J. P., and E. Grim. Canine gastric blood flow and its distribution. Amer. J. Physiol. 1964, 207, 1195.

25. Mall, F. The vessels and walls of the dog's stomach. Johns Hopk. Hosp. Rep. 1896, $1,1$.

\section{SPECIAL NOTICE TO SUBSCRIBERS}

Post Offices will no longer forward the Journal when you move.

Please notify The Journal of Clinical Investigation, Business Office, 10 Stoughton Street, Boston, Mass. 02118, at once when you have a change of address, and do not omit the Zip Code number. 